\title{
"Amar la trama más que el desenlace!" Reflexões sobre as proposições Trama Ecossistêmica da Ciência, Cartografia dos Saberes e Matrizes Rizomáticas, na pesquisa em Turismo "Loving the weave more than the outcome!" Reflections about the propositions Ecosystemic Weave of Science, Cartography of Knowledge and Rhizomatic Matrices, in Tourism Research
}

\section{Maria Luiza Cardinale Baptista}

Professora e pesquisadora do Programa de Pós-graduação em Turismo e Hospitalidade e do Curso de Comunicação Social da Universidade de Caxias do Sul - UCS, Caxias do Sul/RS, Brasil

E-mail: malu@pazza.com.br

Artigo recebido em: 11-10-2019

Artigo aprovado em: 20-04-2020 


\section{RESUMO}

O texto tem caráter ensaístico, apresentando as proposições epistemológico-teóricometodológicas Trama Ecossistêmica da Ciência, Cartografia dos Saberes e Matrizes Rizomáticas, considerando-as como pressupostos investigativos potentes, para Pesquisa em Turismo e suas transversalidades. Complementa-se com o relato de estudos realizados a partir desses pressupostos. Decorre de percursos de entrelaçamento com vários pesquisadores e processos de estudos empíricos, realizados em universidades do Brasil, já com forte vínculo com pesquisadores de, pelo menos, outros seis países. Em termos teóricos, trata-se de proposições transdisciplinares, alinhadas com pressupostos da ciência contemporânea ecossistêmica e complexa, englobando trilhas teóricas, desde a Epistemologia da Ciência (Santos, Maturana e Varela), o Cenário de Mutação da Ciência (Capra, Crema, Morin, Prigogine), estudos sobre a Metodologia da Ciência, construções e desconstruções (Morin, Rolnik, Lopes), Estudos Esquizoanalíticos e ligados às tecnologias (Guattari, Deleuze, Levy e Kerchove) o Turismo (Moesch, Beni, Baptista) e suas transversalidades. A estratégia metodológica corresponde à associação da Cartografia dos Saberes e Matrizes Rizomáticas, com aproximações e ações investigativas, vivenciadas em estudos próprios e de supervisão de pesquisas. O título, "Amar la trama más que el desenlace!" faz referência a uma canção de Jorge Drexler, sugerindo a importância dos entrelaçamentos dos saberes, nos diversos campos de enunciação. Nesse sentido, entende-se que Ciência, Arte e Saberes Comuns cotidianos são componentes de uma teia-trama, a ser conhecida, reconhecida e valorizada. As proposições apresentadas sinalizam para a relevância de investir nos vínculos de saberes, mais que nas separações, reconhecendo a potência dos microssinalizadores, que vão delineando inflexões dos caminhos da pesquisa.

Palavras-chave: Turismo. Trama Ecossistêmica. Cartografia Dos Saberes. Matrizes Rizomáticas.

\section{ABSTRACT}

The text has an essayistic character, presenting the epistemological-theoreticalmethodological propositions Ecological System of Science, Cartography of Knowledge and Rhizomatic Matrices, considering them as powerful investigative assumptions, for Tourism Research and its transversalities. It complements the report of studies carried out based on these assumptions. It results from intertwining paths with various researchers and empirical study processes, carried out in universities in Brazil, with a strong link with researchers from at least six other countries. In theoretical terms, these are transdisciplinary propositions, aligned with assumptions of contemporary ecosystemic and complex science, encompassing theoretical paths, from the Epistemology of Science (Santos, Maturana and Varela), the Science Change Scenario (Capra, Crema, Morin, Prigogine), studies on the Methodology of Science, constructions and deconstructions (Morin, Rolnik, Lopes), Schizoanalytic Studies and related to technologies (Guattari, Deleuze, Levy and Kerchove) Tourism (Moesch, Beni, Baptista) and their transversalities. The methodological strategy corresponds to the association of the Cartography of Knowledge and Rhizomatic Matrices, with investigative approaches and actions, experienced in own studies and research supervision. The title, "Loving the weave more than the outcome!" refers to a song by Jorge Drexler, suggesting the importance of the intertwining of knowledge, in the various fields of enunciation. In this sense, it is understood that everyday Science, Art and Common Knowledge are components of a web-weave, to be known, recognized and valued. The propositions presented indicate the 
relevance of investing in the bonds of knowledge, more than in the separations, recognizing the power of the micro signals, which outline the inflections of the research paths.

Keywords: Tourism. Ecosystem Weave. Cartography Of Knowledge. Rhizomatic Matrices.

\section{INTRODUÇÃO}

Para apresentar a 'trama' deste texto, posso dizer que ele é um metatexto, que se propõe como trama, até porque isso é inerente ao texto e é disso que venho tratando há muitos anos: de processos de escrita como teia-trama de inscrição de si mesmo (Baptista, 2000) e de uma Ciência que se produz em tramas e enredamentos ecossistêmicos, em caosmose, campo de materialidades, fluxos e energias, que confluem e se dissipam (Baptista, 2017). Assim, o texto intitula-se 'trama' - "Amar la trama más que el desenlace!" - e apresenta uma discussão que tem a trama como centro caosmótico complexo. Desse modo, a 'viagem trama textual' não é simples, mas me parece interessante, para pensar o campo de investigações turísticas, visando compreender conexões e sinalizar possibilidades de discussão epistemológica. Trato, então, aqui, de refletir sobre as proposições epistemológico-teóricometodológicas Trama Ecossistêmica da Ciência, Cartografia dos Saberes e Matrizes Rizomáticas, que venho construindo, vivendo, propondo, considerando-as como pressupostos investigativos potentes, para Pesquisa em Turismo e suas transversalidades.

Nesse sentido, o verso da canção de Jorge Drexler me parece inspirador. Também porque falo desde o lugar de alguém que vem pesquisando e repensando o amor, como ética da relação e do cuidado. Assim, "amar la trama más que el desenlace” tem um sentido profundo, para a vida e para a vida da produção científica, também para compreender o turismo e suas implicações transversais. Fenômeno plural, complexo, o turismo me parece ser, na sua essência desterritorializante, metáfora para a pesquisa e a vida, numa lógica espiralada, em que não se sabe ao certo onde se encontra o ponto de início, os pontos de confluência ou de passagem, para lembrar Prigogine (2009) e seus ensinamentos sobre as estruturas dissipativas.

"Amar la trama mas que el desenlace”, como título, pode ser lido, neste texto, como amar o processo e seus enredamentos, mais que o desfecho da pesquisa. Compreender que o sentido se faz no percurso e nos liames, que vão se produzindo no caminho, nos sinalizadores do percurso, que vão marcando nossos corpos, nossos passos, compondo a inscrição das nossas marcas nos ecossistemas que percorremos e carregamos conosco. Diz o próprio Drexler (2017): 


\section{"Somos una especie en viaje \\ No tenemos pertenencias, sino equipaje \\ Vamos con el polen en el viento \\ Estamos vivos porque estamos en movimento".}

Aqui vale uma reflexão sobre a presença das letras das canções em um texto científico, teórico, reflexivo sobre questões epistemológicas e metodológicas. O que pode causar alguma estranheza, para alguns pesquisadores, na verdade é coerente com o que digo aqui e venho propondo, nas produções científicas e nos relatos dos meus estudos. A dimensão ecossistêmica, pautada pela lógica da ecologia profunda, em conexão com autores como Capra (1991; 1997), Prigogine (2009), Crema (1989), Lima (1998), Santos (1998) Santos e Meneses (2009), Maturana (1998), Maturana e Varela (1997), (Guattari, 1992), Deleuze e Guattari (1995), Guattari e Rolnik (1986), Monteiro e Colferai (2011), me ajudam a compreender o alinhamento com uma ciência que se produz no movimento e nos entrelaçamentos ecossistêmicos, em sentido amplo. Assim, também, "amar la trama más que el desenlace" significa amar a trama de saberes, as conexões muitas, múltiplas também com os saberes comuns, cotidianos, de outros campos de produção, de outros ecossistemas, por assim dizer.

Nesse sentido, saberes arcaicos de comunidades tradicionais como os indígenas, saberes comuns cotidianos da sabedoria popular, saberes percebidos pelo contato com a arte, em sentido amplo, podem ser considerados em acoplamento com os saberes produzidos pela Ciência em campos acadêmicos, nas produções científicas, que, diga-se de passagem, para mim, só fazem sentido em alinhamento e conexão profunda com o mundo da vida, do Ecossistema todo, do Universo. Vale ressaltar que, quando falo do Universo, não é uma força de expressão, mas o Universo mesmo, já que a Ciência Contemporânea vem apontando para a relevância de se fazer e pensar nas macro conexões. Um pensador nesse sentido é Marcelo Gleiser, professor titular de física e astronomia no Dartmouth College, em New Hampshire (EUA), ganhador do Prêmio Templeton, considerado o "Nobel do diálogo entre a ciência e a espiritualidade".

Cartografia dos Saberes e Matrizes Rizomáticas são proposições minhas, que decorrem de quase 30 anos de ensino de Metodologia da Pesquisa e do desejo de ajudar os pesquisadores iniciantes a se orientarem nas viagens investigativas que escolhem. Lembro-me sempre da primeira aula que dei, em uma Universidade, no caso, na Universidade de Taubaté, em 1990. Era uma aula de Teorias e Método de Pesquisa em Comunicação, encontrei os alunos, todos, sentados perto da parede, onde ficava a porta da sala. Aos poucos, fui 
entendendo que a geografia de sala de aula também é um texto, que demonstra o desejo e a disposição dos estudantes, para a interação entre eles mesmos e com o educador. Assim, daquele momento em diante fui entendendo que o mundo da pesquisa, antes de ser um desejo é um enigma, um fantasma, que desafia o viajante iniciante. Daí em diante, comecei a pensar em estratégias de acionamento do desejo e de orientação na viagem da investigação.

Naquela época, eu vivia o encontro teórico com Jesus Martin Barbero, referência importante na área da Comunicação. No Livro De los medios a las mediaciones (1998), ele diz que é preciso refazer os mapas, repensar os lugares de onde são feitas as perguntas e diz que, talvez, fosse necessário fazer um 'mapa noturno', de onde se pudesse ver o que não tinha sido visto até então, nos estudos em Comunicação. Eu fiquei, então, com a ideia ecoando em mim, sobre a importância de ter mapas para as viagens investigativas.

Em 1993, já de volta a Porto Alegre, interessei-me por um curso sobre Processos Grupais, coordenado por Ligia Hecker Ferreira e Carmem Oliveira, em um lugar emblematicamente chamado "Espaço de Vida". Ali tive meu primeiro contato com os textos de Félix Guattari, Gilles Deleuze e Suely Rolnik. No texto Cartografia Sentimental, de Rolnik de 1989, encontrei a metáfora da cartografia para pensar uma estratégia metodológica. Aprendi ser possível e interessante pensar em cartografias psicossociais, em uma variação do conceito originário da Geografia, como ciência da representação gráfica da superfície terrestre, tendo como produto final o mapa. Assim, a cartografia é o processo, envolve concepção, produção, difusão, utilização e estudo dos mapas, é o todo, o mapa é a materialização do desenho da delimitação geográfica, a partir do estudo nessa lógica holística e processual.

Rolnik (1989) explica que a cartografia é um mapa que se faz acompanhando a mudança da paisagem, o que ajuda a pensar nas pesquisas e na viagem investigativa, em seu processo mutante, marcado pelas transformações da sequência de inusitados acontecimentos em potência. Em pesquisa e em viagem, tudo pode (e deve) ser pensado, planejado, desde que saibamos que, a despeito do esforço e esmero de planejamento, é preciso estar atento para o movimento espontâneo do 'acontecimento turístico, viajante, investigativo'. No caso da pesquisa, às vezes, parece que o objeto de estudo toma as rédeas do processo e vai nos mostrando meandros, linhas de fuga, rotas novas, e nós precisamos ter sensibilidade, coragem e ousadia para 'ler' esses sinais e empreender novos percursos, não imaginados no início da pesquisa. Eu costumo dizer que, na viagem, na pesquisa e na vida, perder-se nos percursos também faz parte do processo, não é necessariamente ruim. Muitas vezes, ao contrário, é 
justamente o momento de passagem entre algo presumido e com limitações, para belas descobertas investigativas ou existenciais.

Assim, graças à proporção da minha curiosidade epistemológica, para lembrar Paulo Freire (1996), meu desejo de compreender processos, vivi o encontro com a perspectiva esquizoanalítica de Suely Rolnik, Félix Guattari e Gilles Deleuze, que me ensinou que, mais que um mapa, é necessário produzir cartografias. Nos textos desses autores, também encontrei o conceito de Rizoma, originário da botânica, mas que pode ser lido como uma brotação que deriva, sem que se tenha certezas do seu rumo, algo como aquelas plantas trepadeiras, que vão se fixando em muros e paredes, crescendo aleatoriamente, a partir de nós de conexões e passagens. O rizoma, então, passou a ser pensado como uma outra bela metáfora para ajudar a compreender os caminhos vários (também os caminhos da pesquisa). Daí deriva a proposição conceitual 'matrizes rizomáticas', na tentativa de explicar que a pesquisa tem seus rumos, suas inflexões e precisa ser pensada nesse sentido, só que isso ocorre de modo fluente, como processo líquido dos rios amazônicos. O direcionamento não pode ser contido ou fixado, apenas presumido, a partir de sinalizadores, e lido, na sua 'dança da vida', na emergência sequenciada de acontecimentos, que se engrendram no processo, no caminho.

Bem, vamos adiante. Para este texto, o rizoma inscriacional segue os sinalizadores do título Trama Ecossistêmica da Ciência, Cartografia dos Saberes e Matrizes Rizomáticas, na Pesquisa em Turismo. São esses os nós de confluência em passagem do texto e da discussão aqui apresentada. Vamos a eles, então.

\subsection{Pressupostos: Trama Ecossistêmica da Ciência e do Turismo}

A proposição conceitual Trama Ecossistêmica da Ciência deriva dos pressupostos da visão sistêmica e complexa contemporânea. Tem relação direta com o conceito de comunicação que propus, quando da produção de uma tese na Universidade de São Paulo.

Comunicação é interação de sujeitos, através do fluxo de informações entre eles,
numa espécie de trama-teia complexa, composta tanto de elementos visíveis quanto
invisíveis, corporais e incorporais, significantes e a-significantes, podendo ser ou
não mediada por dispositivos tecnológicos, na constituição de algo como um campo
de força de encontro de energias, decorrente dos universos de referência de cada
sujeito envolvido. Quer dizer, encontro de universos de sujeito, universos subjetivos.
(Baptista, 2000, pp. 33-34).

Há neste conceito, a ênfase à interação - conexão -, ao pressuposto de fluxos constantes, de existência e importância de elementos visíveis, materiais, invisíveis, imateriais, passíveis e não passíveis de representação, elementos que escapam ao reducionismo do concreto, portanto. Presente, também, no conceito, a compreensão da possibilidade de 
ingerências e mediações dos dispositivos tecnológicos, na composição de um campo de forças de energias, nos encontros de universos de referências de cada sujeito, que eu prefiro pensar, agora, universos ecossistêmicos.

Fica evidente que o conceito resulta da compreensão da lógica ecossistêmica. A aproximação com essa lógica ocorreu em um processo de longa data, especialmente desde a década de 1990, quando do contato com os textos de Capra, Roberto Crema, entre tantos outros autores. Depois, foi se consolidando, até que, mais tarde, na Amazônia, em 2010, pude me deparar com o conceito de ecossistemas comunicacionais, de Gilson Monteiro, que orientava a Pós-Graduação em Ciência da Comunicação, numa perspectiva de vanguarda da UFAM, em relação aos estudos em Comunicação no Brasil. Assim, pensar em ecossistemas comunicacionais, na perspectiva da ecologia profunda, em um ambiente como a Amazônia, me ajudou a compreender porque eu já vinha dizendo, há mais de 20 anos, intuitivamente, que fazer pesquisa é como fazer uma viagem na floresta. Eu dizia, porque sentia, mas não necessariamente compreendia plenamente. Foi ali, em meio às árvores e os sons da floresta que eu compreendi a pequenez do humano, a minha própria condição de miúda existência e a profunda conexão de tudo com tudo, os desafios do inusitado instante, o acontecimento da viagem, o momento em que a natureza e as conexões cósmicas vão dizendo os caminhos e os descaminhos, vão explicando porque você está ali, e não em outro lugar, sem que isso tenha sido planejado conscientemente, em sua totalidade, mas, ao mesmo tempo, que poderia ser presumido e percebido nas inflexões do próprio caminho, desde que soubesse ler as matrizes rizomáticas, que vou explicar mais adiante.

Vale aqui a fala de Colferai, em tese orientada por Gilson Monteiro, emblematicamente intitulada Um jeito amazônida de ser mundo:

[...] o que há de mais fundamental no Ecossistema Comunicacional: a inseparabilidade entre natureza, sociedade e as sensibilidades amplificadas [grifos do autor] pelos suportes tecnológicos da comunicação e informação. Uma vez admitida esta inseparabilidade, pode ser percebida com clareza a penetração, por continuidade, de princípios do meio natural na tecnologia [grifos do autor]. Há o acoplamento entre o ambiente e o homem, mas também com e nas tecnologias que amplificam a cognição, que alteram a percepção do tempo e do espaço [grifos do autor]. A psicologia encontra a tecnologia e faz ampliar as sensações, faz extrapolar o ecossistema físico para o virtual, mas sem perder a percepção sensorial. Há aí uma corporalidade tecnocognitiva [grifos do autor], sem preponderância de um elemento sobre o outro, e torna-se possível a abordagem do Ecossistema Comunicacional a partir de qualquer um destes pontos. (Colferai, 2014, p. 23).

Desse modo, sensível à paisagem amazônica encontrei conceitos e pressupostos que já vinha trabalhando há muitos anos, mas que, ali, estavam consolidados em projetos, propostas várias, sendo, inclusive, enunciados na área de concentração de um programa de Pós- 
Graduação. A aproximação com a Amazônia tem sido intensa, desde 2010. Durante o ano de 2015, fui pesquisadora Visitante Sênior, Professora Colaboradora do Programa de PósGraduação em Ciências da Comunicação (PPGCCOM) e Pós-Doutoranda em Sociedade e Cultura da Amazônia (PPGSCA). Desenvolvi atividades a convite da Reitoria, "Projeto UFAM, Eu Cuido!”, Oficinas com Pós-Graduação em Serviço Social! Sou ainda hoje docente colaboradora do Programa de Pós-Graduação em Sociedade e Cultura da Amazônia.

Na Universidade de Caxias do Sul, na Pós-Graduação em Turismo e Hospitalidade, venho desenvolvendo pesquisas no viés epistemológico-teórico-metodológico, que vem sendo ampliado a partir do trabalho com diferentes platôs investigativos. Destaco nesse sentido, a sequência de estudos, desde o ano de 2003: "Desterritorização Desejante em Turismo e Comunicação" (com apoio do CNPq); "Trama Amorcomtur! Complexos processos comunicacionais e subjetivos, que potencializam o turismo, considerados sobre o viés da amorosidade e autopoiese"; e Ecossistemas Turístico-Comunicacionais-Subjetivos: sinalizadores teórico-metodológicos, no estudo de ecossistemas turístico-comunicacionaissubjetivos, considerados a partir de sua característica ecossistêmica, caosmótica e autopoiética.

A noção de ecossistema aqui está relacionada à visão da ecologia profunda. Para a Biologia, a noção de ecossistema inclui tanto fatores bióticos (vivos: animais, plantas, bactéria entre outros) quanto abióticos (ambiente físico) inter-relacionados dinamicamente. Nesse sentido, implica reconhecer o conjunto dos relacionamentos mútuos entre os seres vivos e o meio ambiente, contínuo dinamismo, o fato de que o ecossistema não é determinado por seu tamanho, mas por sua estrutura e seus padrões de organização. Eu diria, por sua "trama-teia" constituinte, no lugar de 'estrutura', suas inflexões, direcionamentos e os múltiplos pontos de passagem e de confluência.

Por esse ângulo, falar em ecossistema comunicativo, turístico e subjetivo implica buscar a descentralização de vozes, a dialogicidade de fatores bióticos e abióticos, a interação. As relações devem buscar equilíbrio fluente e harmonia em ambientes onde convivem diferentes atores. Assim, não é apenas no mundo natural ou no tecnológico que atua o ecossistema comunicativo, turístico e subjetivo, mas em todas as esferas dessas áreas. Dessa linha de pensamento, deriva a compreensão dos ecossistemas turístico-comunicacionaissubjetivos como processos complexos de desterritorializações, envolvendo o acionamento e entrelaçamentos de diferentes ecossistemas, em que o sujeito que se desloca é também sujeito de transposições e transversalizações ecossistêmicas, que agencia a movimentação e conexão de mundos, de universos de significações, de referências, de produção e consumo. Desse 
modo, está envolvida e é acionada uma teia de materialidades e imaterialidades, desde as potentes tramas econômico-político-sociais-culturais e de prestação de serviços, até os subjacentes fluxos de energias, das micropartículas, de acionamento quântico, que atingem também os níveis de afetos. Com o turismo, tudo se movimenta e se transforma, ao mesmo tempo que o movimento de desterritorialização, em si, autopoietiza (reinventa) sujeitos e lugares, das dimensões ecossistêmicas envolvidas.

No percurso como pesquisadora do Turismo, pude observar confluência desse campo transdisciplinar com tantos outros que me são tão próximos, que se fazem presentes, como ênfase, nos meus estudos. Entendi, também, que o campo de saberes turísticos passou pelo 'tratamento' do que eu chamo de engrenagem maquínica capitalística, inspirada nos estudos esquizoanalíticos de Guattari (1992) e Guattari e Rolnik (1986). O conceito também tem história alinhada com o processo de desenvolvimento da humanidade e marcada pelos processos capitalísticos. Ciência, mundo da vida, modo de produção, circulação de bens e consumo compõem uma "trama-teia" de engendramentos, que precisa ser compreendida na sua complexidade e na grandiosidade dos seus liames, visíveis e invisíveis. Desse modo, empenhada em produzir saberes, em produzir Ciência, penso que a perspectiva trama ecossistêmica é caosmótica, desterritorializante e complexa. Nesse sentido, é quase uma negação da ideia de um campo científico específico, porque reconhece as singularidades do lugar de onde se olha o mundo, mas propõe sempre que, desde esse lugar, sejam consideradas as conexões múltiplas e as interações intra e exteriores como componentes essenciais.

$\mathrm{Na}$ lógica fluente dos saberes cotidianos, reconheço a essência, que se expressa na 'viagem'. Isso implica em estratégias de produção e de tomada de decisões, para as quais proponho a Cartografia dos Saberes e as Matrizes Rizomáticas.

\section{ESTRATÉGIA METODOLÓGICA CARTOGRAFIA DOS SABERES E MATRIZES}

\section{RIZOMÁTICAS}

Como referi, Cartografia dos Saberes é uma proposição minha, para ajudar a organizar a produção da pesquisa. Seria apropriado dizer que cartografia aqui é mais propriamente o desenho dos 'descaminhos' da pesquisa. Também por isso prefiro chamar de 'estratégia metodológica'. Cartografia não é um método, porque método é caminho. Não é metodologia, porque metodologia é o estudo dos caminhos. É uma estratégia de vislumbre e organização dos caminhos, das trilhas. É o desenho da 'trama de trilhas'. Essas trilhas são simultâneas e transpassadas. Elas se interconectam, se entrelaçam, mas podem ser apresentadas, como 
processos de percursos e levantamentos de informações sobre saberes. Daí, Cartografia dos Saberes. Trama das trilhas investigativas, por onde o pesquisador vai se embrenhando para coletar os dados, em si mesmo, nas teorias, nos percursos de aproximações e ações investigativas, considerando a dimensão intuitiva da pesquisa. Assim, nessa "teia-trama" de caminhos e descaminhos da pesquisa, previ quatro trilhas investigativas, assim denominadas: trilha de saberes pessoais, trilha de saberes teóricos, trilha usina de produção e trilha dimensão intuitiva da pesquisa.

$\mathrm{Na}$ lógica do reconhecimento da floresta de conhecimento, procura-se definir, de saída, alguns 'nós informativos' (palavras-chave, na linguagem da ciência tradicional). Sobre esses 'nós', é preciso descobrir os enlaces internos dos sujeitos. Quer dizer, o que sujeito autor da pesquisa pensa e sente e sabe até o momento, sobre estas pistas, esses 'nós sinalizadores' ou, como diria Prigogine (2009) "nós de confluência ou de passagem". Também é preciso ir fazendo inscrições sobre o que vier, deixando para depois a compreensão sobre o vínculo ou não com os 'nós' reconhecidos no início.

A trilha de saberes pessoais parte do pressuposto de que a pesquisa surge dos caminhos percorridos pelo pesquisador e de seus caminhos internos. Há aí grandes pistas para o caminho que há de vir, para o devir pesquisa. É preciso, então, pacientemente, percorrer esses descaminhos, a partir de alguns procedimentos inerentes a esse processo de busca: produção de texto com resgate de lembranças; produção de diário de bordo (de pesquisa); resgate e análise de fotografias e vídeos pessoais, para retomada de informações e ampliação da sensibilização para a temática da pesquisa; resgate de poemas, canções e todo e qualquer registro de materialidade, que possa trazer informações sobre os 'nós' da pesquisa; eventual retomada de documentos, para resgate de informações e dados históricos sobre percursos realizados; produção de textos de livre associação, sobre ideias preexistentes, relacionadas às temáticas centrais da pesquisa. Neste último caso, trata-se da produção de textos livres, sem preocupação, sem correção, sem normas, sem filtros, sem controle prévio.

A trilha de saberes teóricos também leva em consideração os "nós investigativos vislumbrados'. O pesquisador parte desses 'nós' e embrenha-se na floresta de dados publicados em livros e periódicos, tentando resgatar o máximo possível de informações, buscando refazer os caminhos dos pesquisadores anteriores, resgatar saberes e ir ‘conversando' com esses autores, compondo com eles a sua própria “trama-teia” teórica. Fazse, então, um desenho trama de trilhas teóricas, a partir dos 'nós iniciais'. Nesse desenho, começa-se a listar as referências de textos, dando destaques para aqueles que são nossas referências escolhidas, no sentido de que são as que mais dialogam com nossos entendimentos 
e visões de mundo. Há de haver uma estreita conversa com os autores, certa intimidade de pensamento, um vínculo, uma comunhão de sentires e pensares, uma cumplicidade. Neste caso, vislumbra-se o desenho dos nossos 'referenciais teóricos consolidados', depois de toda uma revisão bibliográfica. $\mathrm{Na}$ revisão, aproximações investigativas com os dados bibliográficos, reencontramos o que foi produzido. No referencial teórico, apresentamos o que foi escolhido de todo o percurso investigativo pela 'floresta bibliográfica'. Trata-se de escolha, que se faz mais consistente porque decorre de um substrato investigado com profundidade, em entrelaçamento e alinhamento com as outras trilhas.

A trilha denominada Usina de Produção está composta especialmente de dois processos: aproximações e ações investigativas. As aproximações investigativas são ações preliminares, sem planejamento rígido, mas realizadas a partir de movimentos em direção a intuição preliminar. Nos procedimentos das pesquisas da Ciência Tradicional, são realizadas sondagens, pré-testes, antes da aplicação da pesquisa propriamente dita. Na Cartografia dos Saberes, trabalha-se com aproximações, como ações que nos aproximam, mas 'de peito aberto', sem o atrelamento pressupostos rígidos. Reconhece-se, aqui, que o campo tem seus caprichos, suas nuanças, seu caráter de indomável e singular. Não se deixa 'domar' por escalas rígidas apriorísticas. Cada campo é único, ainda que seja transversalizado de elementos de outros campos. Assim, é preciso que o pesquisador, pacientemente, vá sentindo o campo, vá se aproximando como quem se enamora do universo ecossistêmico investigado. É disso, propriamente, que se trata, de uma produção investigativa 'em amor'. Ao longo desses quase 30 anos de investigação, percebo que isso faz muita diferença, nos resultados.

Essas aproximações vão oferecendo subsídios para a composição de uma trama de ações investigativas, pensadas cuidadosamente, sentidas e pressentidas, no campo, em consideração aos objetivos específicos que compõem o objetivo geral, o objeto de estudo e a questão-problema. Percebem-se, assim, alinhamentos e inflexões que compõem o equilíbrio fluente da pesquisa. O texto científico pede coerência interna e essa coerência vai sendo percebida pelas passagens e confluências das trilhas, que se mostram a partir da fluidez dos acontecimentos, na composição de desenhos que expressam, sinalizam os rumos do conhecimento. Desse modo, dos objetivos específicos brotam trilhas teóricas ou aproximações e ações investigativas, que resultam em florescimento de dados que vão, por sua vez, compor os capítulos. Estes constituem-se em planos de intensidade contínua (platôs) que contribuem para dar densidade ao conhecimento produzido e desembocam, mais adiante, nas considerações finais, nas respostas aos objetivos específicos. Da percepção da necessidade dessa coerência interna e da busca de dar visibilidade para o fluxo rizomático da pesquisa, 
surgiu a proposição das matrizes rizomáticas, sobre o desenho dos rios amazônicos - escolha visual depois de muito tempo de reflexão e buscas imagéticas, para representar o curso dos caminhos e descaminhos da pesquisa, com os riscos de se perder e, ao mesmo tempo, a potencialidade de descoberta de novos mundos do conhecimento.

Figura 1 - Matrizes Rizomáticas

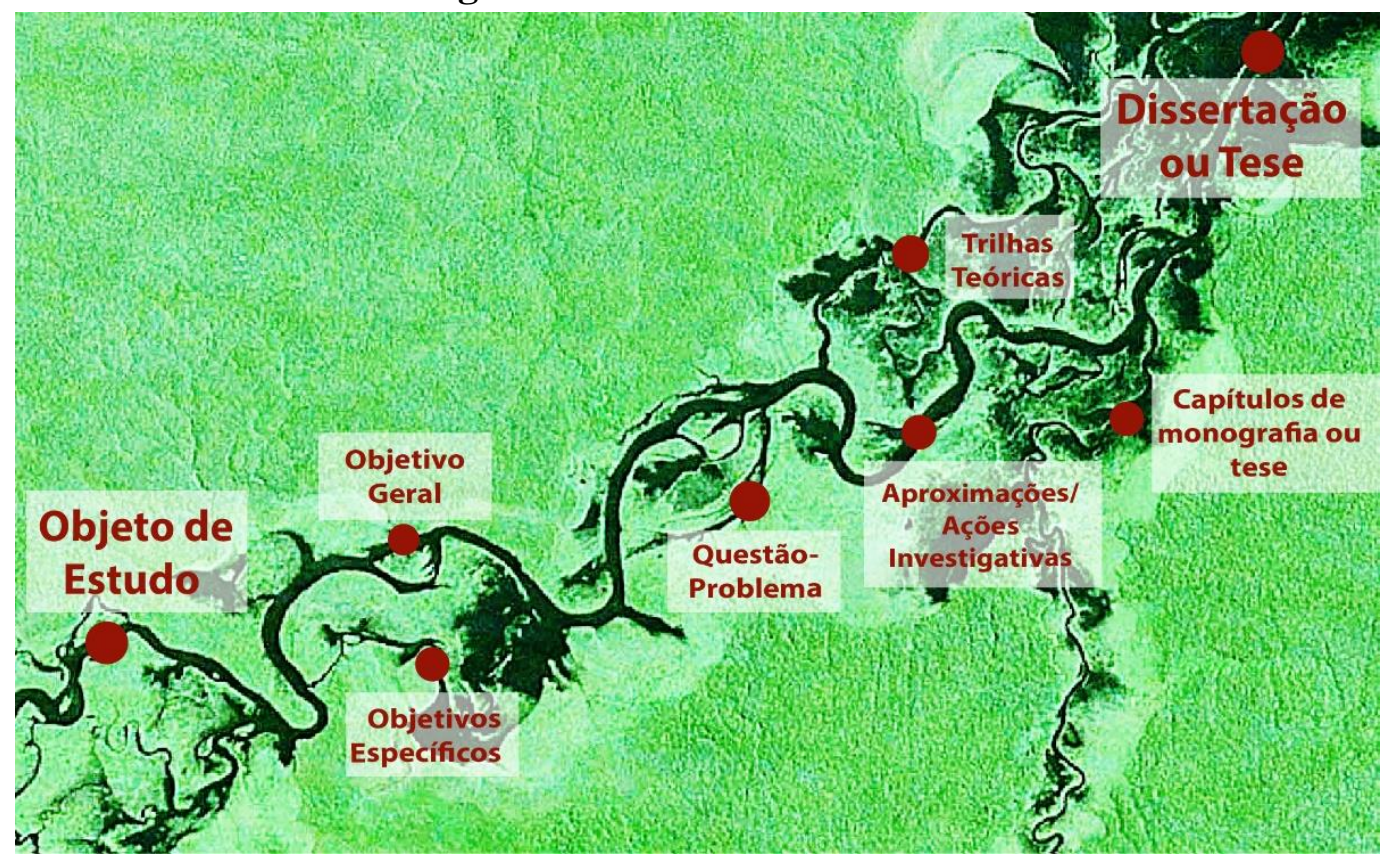

Fonte: Elaborado pela autora, 2019.

Figura 2 - Matrizes: os 3 grandes phylum

Matriz 1: Verificação do 'Equilíbrio Fluente' da Narrativa da Pesquisa

\begin{tabular}{l|l|l|l|l|} 
Título & $\begin{array}{l}\text { Objeto de } \\
\text { estudo }\end{array}$ & $\begin{array}{l}\text { Objetivo } \\
\text { geral }\end{array}$ & $\begin{array}{l}\text { Objetivos } \\
\text { específicos }\end{array}$ & Questão-Problema?
\end{tabular}

Matriz 2: Trama das Trilhas Teóricas - Equilíbrio Fluente das Teorias da Pesquisa

\begin{tabular}{l|l|l|l|l} 
Objetivo geral & $\begin{array}{l}\text { Objetivos } \\
\text { específicos }\end{array}$ & Trilhas teóricas & $\begin{array}{l}\text { Autores para } \\
\text { cada trilha }\end{array}$ & $\begin{array}{l}\text { Capítulos } \\
\text { da } \\
\text { dissertação/tese }\end{array}$
\end{tabular}

ҰMatriz 3: Trilhas da 'Viagem em Ação'- Equilíbrio Fluente das Ações Investigativas

\begin{tabular}{l|l|l|l|}
$\begin{array}{l}\text { Objetivo } \\
\text { geral }\end{array}$ & Objetivos específicos & $\begin{array}{l}\text { Aproximaçóes } \\
\text { e ações } \\
\text { investigativas }\end{array}$ & $\begin{array}{l}\text { Capítulos } \\
\text { da dissertação/tese }\end{array}$ \\
\hline
\end{tabular}

Fonte: Elaborado pela autora, 2019. 


\section{RESULTADOS NA PESQUISA EM TURISMO - PLATÔS INVESTIGATIVOS}

Como resultados, podem ser destacadas pesquisas realizadas com base nesses pressupostos. Os trabalhos listados abaixo foram orientados, em nível de mestrado, tendo resultado, em paralelo, artigos científicos apresentados em eventos no Brasil e em vários países, publicações em livros e periódicos científicos, também com repercussão nacional e internacional.

(2015) Em Ondas com o Turismo: O Olhar da Comunidade sobre o Turismo nas Praias do Farol de Santa Marta (Renan de Lima da Silva) ${ }^{1}$

A dissertação é sobre o turismo nas Praias do Farol, analisado a partir do olhar da comunidade, sobre as relações estabelecidas na atividade. Tem como objetivos caracterizar as práticas turísticas nas praias do Farol; descrever as relações estabelecidas entre os turistas e a comunidade; e observar e discutir os eventuais desdobramentos dessas relações e o turismo da localidade. Trata-se de um estudo transdisciplinar, envolvendo as áreas Turismo, Hospitalidade, Comunicação e Antropologia. A orientação metodológica é qualitativa, de cunho exploratório, com o desenvolvimento de revisão bibliográfica, observação participante com caderno e diário de campo e entrevistas abertas gravadas e transcritas. Em termos de resultados, traz um panorama sobre as desterritoralizações da pesquisa, bem como o turismo e a hospitalidade, segundo o olhar da comunidade, seus medos e pretensões com as práticas. Além disso, apresenta o turismo, nas praias do Farol, como fazer da comunidade, tendo como marca o fato de que o 'localismo' do surfe ajuda na preservação dessa cultura.

(2016) Turismo em Cemitérios. Um Estudo sobre o Cemitério como Patrimônio e Atrativo Turístico, considerando a Ambivalência Morte e Vida das Necrópoles (Charlene Brum Del Puerto $)^{2}$

A dissertação tem como objeto de estudo o cemitério como um atrativo turístico, considerando seu patrimônio e a ambivalência morte e vida das necrópoles. Pretendeu-se,

${ }^{1}$ Silva, R. L. (2015). Em ondas com o turismo: o olhar na comunidade sobre o turismo do Farol de Santa Marta. Dissertação de Mestrado, Programa de Pós-Graduação em Turismo e Hospitalidade, Universidade Caxias do Sul, Caxias do Sul, RS, Brasil.

${ }^{2}$ Puerto, C. B. (2016). Turismo em cemitério. O cemitério como patrimônio e atrativo turístico, considerando a trama morte e vida nas necrópoles. Dissertação de Mestrado, Programa de Pós-Graduação em Turismo e Hospitalidade, Universidade Caxias do Sul, Caxias do Sul, RS, Brasil. 
com este estudo, analisar o cemitério escolhido como um atrativo turístico, considerando seu patrimônio e a ambivalência morte e vida das necrópoles. Em termos teóricos, trata-se de um estudo transdisciplinar, envolvendo aspectos sobre o patrimônio, ambivalência morte e vida, cemitério, turismo e turismo em cemitérios, para entender as relações existentes entre essas temáticas. A metodologia teve orientação qualitativa com aspecto teórico-metodológico transdisciplinar, tendo sido utilizada a Cartografia dos Saberes de Baptista (2014) e aspectos do estudo de caso de Yin. O objeto empírico do estudo foi o Cemitério da Consolação, por ser uma referência em turismo em cemitério no país. Observou-se, na pesquisa, o distanciamento que as pessoas têm da temática sobre a morte; a necessidade de novos estudos sobre o patrimônio, para entender seu significado na atualidade; a necessidade de ampliação sobre o estudo em cemitérios, considerando a dimensão de vida que há nas necrópoles e a importância dos dispositivos de potencialização, ou seja, ações ou aspectos que provocam o deslocamento até as necrópoles. Considera-se que o cemitério possui uma potência de vida pertinente à ambivalência aqui proposta. Essa ambivalência é expressa de várias maneiras: está inscrita nas lápides, presente na vida dos trabalhadores e visitantes da necrópole, em suas buscas e vinculações com o cemitério. Nesse sentido, há uma relação intrínseca entre a potência da ambivalência morte e vida e a atividade turística.

(2017) Jammo in Cantina? C Que Sabe! A Italianidade na Gastronomia Paulistana: Marcas de Hospitalidade e Amorosidade (Carlos Leoni) ${ }^{3}$

Esta dissertação trata da italianidade na gastronomia paulistana, considerando as marcas de hospitalidade e amorosidade, analisadas na "Cantina C Que Sabe!" O objeto empírico corresponde a uma cantina tradicional, estabelecida há mais de 80 anos na cidade, no bairro da Bela Vista, na região conhecida como Bixiga, na cidade de São Paulo, Brasil. A pesquisa realizada é um trabalho transdisciplinar, que transita entre as áreas da HospitalidadeAmorosidade, Gastronomia, Comunicação e História. Trata-se de um estudo de caráter exploratório e qualitativo, desenvolvido a partir da estratégia metodológica denominada Cartografia dos Saberes, por Baptista (2014), cujos pressupostos epistemológico-teóricos são alinhados à Ciência Contemporânea. Considera, neste sentido, o caráter processual, sistêmico e complexo dos fenômenos, a serem analisados, e a importância do reconhecimento da

${ }^{3}$ Leoni, C. (2017). Jammo in Cantina? C Que Sabe! A Italianidade na Gastronomia Paulistana: Marcas de Hospitalidade e Amorosidade. Dissertação de Mestrado, Programa de Pós-Graduação em Turismo e Hospitalidade, Universidade Caxias do Sul, Caxias do Sul, RS, Brasil. 
dimensão subjetiva da pesquisa. Assim, parte do levantamento dos saberes pessoais, dos saberes teóricos, para criar uma Usina de Produção, com aproximações e ações investigativas: entrevista com o proprietário da cantina; visitas ao local para observações sistemáticas; registros fotográficos e análises de manchas visuais, diário de campo e conversas informais. A "Cantina C que Sabe!” apresenta significativas marcas que caracterizam a hospitalidade e a amorosidade, aliadas a diversos aspectos que podem ser percebidos como inerentes à italianidade paulistana. O conjunto de aspectos relacionados a esses três sinalizadores hospitalidade, amorosidade e italianidade - são associados às suas práticas gastronômicas. A Cantina constitui-se, assim, em síntese expressiva da italianidade na gastronomia paulistana e, também, associa a relação desses conceitos com suas práticas gastronômicas.

(2017) Turismo, Hospitalidade e Amorosidade: os Sujeitos-Devotos do Círio de Nossa Senhora de Nazaré em Belém do Pará (Renato Dos Santos Lima) ${ }^{4}$

Esta dissertação tem como objetivo identificar as marcas de hospitalidade e amorosidade nas relações dos sujeitos-devotos do Círio de Nazaré, e sua vinculação com o turismo em Belém do Pará. Em termos teóricos, o texto apresenta a ideia de turismo, hospitalidade, amorosidade e religiosidade, em vista de refletir, novas formas de (re)pensar a produção do saber para o estudo. Como recurso metodológico, apresenta-se uma discussão qualitativa e exploratória, com uso da estratégia metodológica da Cartografia de Saberes, que é uma prática investigativa contemporânea, com uma abordagem transdisciplinar e, portanto, estratégica para a pesquisa em Turismo. Orientada por quatro trilhas assim identificadas: saberes pessoais, saberes teóricos, usina de produção (que se subdivide em dois campos investigativos - aproximações e ações) e a dimensão intuitiva da pesquisa. A parte de campo, envolvendo os sujeitos-devotos, ocorreu na $223^{a}$ edição da Festividade Círio de Nossa Senhora de Nazaré, que se realizou em Belém do Pará, no ano de 2016. Para o estudo, considerou-se como sujeito da pesquisa: a igreja, o corpo organizador da festa, o apoio técnico-teórico e as pessoas que estiveram atuando diretamente em atividades oportunizadas pelo momento de festa. $\mathrm{O}$ problema do estudo, que teve como pergunta: quais as marcas de hospitalidade e amorosidade, nas relações dos sujeitos-devotos, que participam da festividade Círio de Nazaré, e sua vinculação com o turismo em Belém do Pará? As marcas foram percebidas,

\footnotetext{
${ }^{4}$ Lima, R. S. (2017.) Turismo, hospitalidade e amorosidade : os sujeitos-devotos do Círio de Nossa Senhora de Nazaré em Belém do Pará. Dissertação de Mestrado, Programa de Pós-Graduação em Turismo e Hospitalidade, Universidade Caxias do Sul, Caxias do Sul, RS, Brasil.
} 
durante todo o percurso do trabalho, estando intrinsecamente relacionadas às narrativas dos sujeitos, e elas, vinculadas ao sentimento devocional a Nossa Senhora (fatores familiares, religiosos e sociais), de pertença e convivência na participação (traços de acolhimento e hospitalidade) e pela valorização dos traços culturais (tradição e religiosidade popular). Podese destacar, neste ponto, o reconhecimento da importância de conviver com a diferença, pela multiplicidade de sujeitos que participam do evento; a referência ao sentimento de irmandade e de relações familiares, na vinculação com a Nossa Senhora; o caráter plural do evento, que foi se complexificando, ao longo da história, de tal modo a abrir espaço para que todos os interessados, independentemente de condições e características, possam manifestar-se, a sua maneira; o reconhecimento da transformação da cidade, de uma energia que altera Belém e cria um campo energético que envolve a todos os que por ali transitam no período; a própria alusão ao Natal parece sinalizar o reconhecimento de um amor intrínseco ao processo, que também pode ser lido como devoção.

(2017) Turismo, Comunicação e a Perspectiva Trama. Sinalizadores-síntese do Festival Brasileiro de Música de Rua e suas relações com o Turismo em Caxias do Sul (Natalia Biazus) $)^{5}$

A dissertação tem como objetivo discutir a relação do Turismo e da Comunicação, a partir da perspectiva trama, tendo como platô investigativo o Festival Brasileiro de Música de Rua Ano 6 - Etapa Festival na Estação, que aconteceu nos dias 17, 18 e 19 de março de 2017 em Caxias do Sul. Trata-se de um estudo transdisciplinar, envolvendo os campos de Turismo e Comunicação, em suas dimensões complexas e carácter dinâmico. A perspectiva da 'trama' está relacionada aos estudos de Baptista e à concepção epistemológica proposta pelo físico austríaco Capra. O Turismo, tem como base as discussões de Marutschka Moesch, Maria Luiza Cardinale Baptista e Susana Gastal. A Comunicação parte do conceito trama, tendo como base a perspectiva 'comunicação-trama' de Baptista. O trabalho foi realizado com orientação metodológica cartográfica, com base na proposição da Cartografia Sentimental, de Rolnik, e na Cartografia de Saberes de Baptista. Com isso, realizou-se cartografar cenas que apresentem sinalizadores-síntese do Festival Brasileiro de Música de Rua, envolvendo Turismo e Comunicação em Caxias do Sul. Em termos operacionais, as cenas envolveram

\footnotetext{
${ }^{5}$ Biazus. N. (2017). Turismo, Comunicação e a Perspectiva Trama. Sinalizadores-síntese do Festival Brasileiro de Música de Rua e suas relações com o Turismo em Caxias do Sul. Dissertação de Mestrado, Programa de PósGraduação em Turismo e Hospitalidade, Universidade Caxias do Sul, Caxias do Sul, RS, Brasil.
} 
entrevista, observação participante, análise de texto jornalístico e anotações em diário de campo, em associação ao levantamento bibliográfico. Como resultado, há a descrição de seis cenas que passaram pela ação metodológica de decupagem, por fim, a reflexão a partir das cenas em conexão aos conceitos de Turismo e Comunicação. Percebe-se, a partir das cenas e do referencial teórico trabalhado, que o Festival Brasileiro de Música de Rua apresenta sinalizadores com relação às características de Caxias do Sul como espaço para o turismo, e aos modos de produções de um evento artístico cultural que desafiam padrões e modelos préexistentes. Além disso, fica evidente a forte conexão do Turismo e a Comunicação em sua dimensão de trama complexa.

\section{(2017) Dança Circular: um corpo que se expressa e acolhe (Newton Fernandes de Ávila) ${ }^{6}$}

Esta pesquisa propõe a dança circular, como expressão de vínculos de acolhimento e amorosidade, em condições de oferecer sinalizadores para a hospitalidade. Tem como objetivos específicos: apresentar a dança circular num contexto relacional entre os sujeitos; relacionar os conceitos de acolhimento e amorosidade à dança circular; identificar sinalizadores de hospitalidade, nos vínculos marcados pelo acolhimento e amorosidade, em decorrência da dança circular. Em termos teóricos, é transdisciplinar, envolve estudos sobre dança circular, corpo, hospitalidade, acolhimento e amorosidade. A Cartografia de Saberes, proposta por Baptista, é a orientação metodológica para a produção deste estudo, com realização das trilhas de saberes pessoais, saberes teóricos e a usina de produção. Foram realizadas aproximações investigativas, com levantamento bibliográfico, aplicação de intervenções de dança em diversos ambientes e observação do corpo participante. Nas ações práticas, observação direta, observação participante, rodas de conversa, relatos de vivências e experimentação com aplicação da dança circular. Os resultados indicaram que a aplicação da dança circular, em diversos ambientes, proporcionou, aos sujeitos participantes, sensação de bem-estar, laços de proximidade, acolhimento e amorosidade. A dança circular é uma forma de integrar o corpo e sua expressividade, em situação de comunicação e expressão. É capaz de acionar o pensamento e explorar a criatividade, para improvisar e, ao mesmo tempo, estabelecer a conexão de troca com este 'outro', o desconhecido. Trata-se de prática cooperativa, envolvendo uma nova-velha forma de lidar com as relações humanas em equipes de trabalho e no cotidiano, certamente como faziam nossos ancestrais. Proporciona sensação

${ }^{6}$ Ávila, N. F. (2017). Dança Circular: um corpo que se expressa e acolhe. Dissertação de Mestrado, Programa de Pós-Graduação em Turismo e Hospitalidade, Universidade Caxias do Sul, Caxias do Sul, RS, Brasil. 
de pertencimento e provoca soltura nos corpos, relaxamento e relação-convívio. Há ampliação do bem-estar físico, mental, emocional, energético e social, no processo que costura as relações interpessoais. Ao tocar e ser tocado na dança circular, há a inserção da permissão de envolvimento, fluidez necessária para a constituição das emoções, do acolhimento e da amorosidade, que, por sua vez, terá resultados diferenciados, gerando condições de hospitalidade.

(2017) Aturá: Trançado de Saberes Amazônicos. Estudo de Caso da Rádio Tribos do Norte (Adriano Silva Rodrigues) $^{7}$

Este trabalho discute o uso das redes sociais pelos indígenas, considerado sob o viés dos Ecossistemas Comunicacionais - Estudo de Caso Rádio Tribos do Norte. Postagens compartilhadas pelos Índios revelam muito sobre como pensam e como agem no ambiente virtual e partir desses materiais foi possível compreender os ecossistemas comunicacionais, analisar saberes indígenas pensados nas redes sociais e discutir a interação complexa dessa comunicação. A pesquisa apresenta interconexões de assuntos relacionados a questões indígenas, Amazônia e redes sociais. O título "aturá" foi empregado, metaforicamente pela razão de estar envolvendo, entrelaçando assuntos que convergem para um mesmo local - a perspectiva do olhar do pesquisador. O recurso metodológico utilizado foi a Cartografia de Saberes por ser a abordagem mais adequada para se pesquisar num ambiente de complexidades, como a Amazônia, permitindo que acontecimentos de diferentes saberes possam interligar e relacionar percepções pessoais e saberes teóricos com a realidade virtual vivenciada pelos Índios dentro das redes sociais. As novas tecnologias expandiram significativamente o acesso a informações, que passaram a estar disponíveis alterando o ambiente sociocultural dos povos indígenas e, consequentemente, transformando a maneira deles se comunicarem.

\footnotetext{
${ }^{7}$ Rodrigues, A. S. (2017). Aturá: Trançado de Saberes Amazônicos. Estudo de Caso da Rádio Tribos do Norte. Dissertação de Mestrado, Programa de Pós-graduação em Ciências da Comunicação, Universidade Federal do Amazonas, Manaus, AM, Brasil.
} 
(2018) Garibaldi: Destino Cinematográfico! Um Estudo sobre a Relação entre Cinema e Turismo no Município de Garibaldi/Rs (Vanilson Pereira Silveira) ${ }^{8}$

Esta dissertação tem como objetivo analisar a relação entre cinema e o turismo, tendo como lócus de análise o município de Garibaldi, localizado na Serra Gaúcha. Em termos teóricos, envolve uma abordagem transdisciplinar, com estudos de Turismo relacionados à comunicação, mais especificamente ao cinema. A metodologia segue a perspectiva qualitativa e exploratória, constituída através da estratégia metodológica da Cartografia de Saberes, proposta por Baptista (2014), através de uma abordagem transdisciplinar, cujos pressupostos teóricos estão alinhados à Ciência Contemporânea. As ações investigativas envolvem: uma revisão bibliográfica para abordagem conceitual da temática, entrevista com representante da Secretaria de Turismo e Cultura e da Garibaldi Film Commission, levantamento das produções filmadas em Garibaldi e análise do filme - O filme da Minha Vida. Em termos de resultados da investigação, é possível apontar o cinema como um importante recurso para o turismo, capaz de promover e divulgar lugares, até então desconhecidos pelos viajantes. Através de suas imagens, a mídia mobiliza os espectadores e desperta o interesse para o que vem sendo discutido como Turismo Cinematográfico, Cineturismo, dentre outras terminologias, envolvendo a visitação de lugares e sets de filmagem que serviram de cenários para produções de filmes e séries cinematográficas ou televisivas. Em Garibaldi, a produção de filmes pode ser considerada como um diferencial estratégico, no posicionamento do município. A elaboração de produtos e serviços vinculados às produções envolve a possibilidade de diversificar e complementar o cenário turístico local. A criação da Garibaldi Film Commission, em 2015, contribuiu de forma significativa para captar novas produções cinematográficas para a região. A imagem do município atrelada à história e a cultura dos imigrantes, identificada nas produções através das locações, encontra-se entrelaçada ao roteiro das diferentes produções que ocupam o território para encenar suas tramas ficcionais. $\mathrm{O}$ cinema, além de promover e divulgar as potencialidades turísticas do município, reforça a vocação de Garibaldi como destino cinematográfico.

\footnotetext{
${ }^{8}$ Silveira, V. P. (2018). Garibaldi: Destino Cinematográfico! Um Estudo sobre a Relação entre Cinema e Turismo no Município de Garibaldi/RS. Dissertação de Mestrado, Programa de Pós-Graduação em Turismo e Hospitalidade, Universidade Caxias do Sul, Caxias do Sul, RS, Brasil.
} 
(2018) Caminhada Noturna do Turismo Tramas Subjetivas e Comunicacionais no Processo de Desterritorialização (Camila Carvalho de Melo) ${ }^{9}$

Essa dissertação tem como objetivo geral identificar sinalizadores subjetivos e comunicacionais, no processo de desterritorialização de um grupo de sujeitos, verificando as suas contribuições para o Turismo. Vincula-se ao Amorcomtur! - "Grupo de Estudos em Comunicação, Turismo, Amorosidade e Autopoiese!", e também aos projetos "Trama AMORCOMTUR! Complexos processos comunicacionais e subjetivos, que potencializam o Turismo, considerados sobre o viés da amorosidade e autopoiese", e "Ecossistemas TurísticoComunicacionais-Subjetivos: Sinalizadores Teórico-Metodológicos, no estudo de ecossistemas turístico-comunicacionais-subjetivos, considerados a partir de sua característica ecossistêmica, caosmótica e autopoiética", desenvolvido na graduação em Comunicação Social e no mestrado em Turismo e Hospitalidade da Universidade de Caxias do Sul (Brasil), Programa de Pós-Graduação. A estratégia metodológica utilizada é a Cartografia de Saberes, proposta por Baptista (2014), considerando uma lógica de pesquisa complexa-ecossistêmica. Destaca-se, neste caso, a realização de aproximações e ações investigativas durante o desenvolvimento da pesquisa. No que se refere às aproximações, podem se ressaltados os resgates de saberes pessoais, registro de conversas em diário de pesquisa, levantamento bibliográfico e roda de conversa com o grupo pesquisado. Em relação às Ações investigativas, ocorreu a observação participante e sistemática da Trilha Noturna de Criúva; roda de conversa com participantes do "Amorcomtur!"; produção de relatos sobre a observação e realização de quadros-síntese. Como resultados, observa-se que os sinalizadores subjetivos e comunicacionais, identificados no processo de desterritorialização, orientam para uma prática turística que considera os sujeitos em suas singularidades. Com isso, entende-se que o desafio da chegada, o medo de se perder e o reconhecimento do local configuram uma matriz, presente no processo de deslocamento dos sujeitos, que pode ajudar a refletir sobre práticas turísticas coerentes com cada momento.

\footnotetext{
${ }^{9}$ Melo, C. C. (2018). Caminhada Noturna do Turismo Tramas Subjetivas e Comunicacionais no Processo de
} Desterritorialização. Dissertação, Universidade Caxias do Sul, Caxias do Sul, RS, Brasil. 
(2019) Hostel: Território de Hospedagem marcado pela Trama Turístico-Comunicacional (Mara Regina Thomazi) ${ }^{10}$

Esta dissertação tem como objetivo geral apresentar sinalizadores da relação do hostel, como território de hospedagem, com a trama turístico-comunicacional. Em termos teóricos, tem abordagem transdisciplinar, englobando o Turismo e a Comunicação, numa perspectiva complexo-ecossistêmica. A estratégia metodológica utilizada é a Cartografia de Saberes, proposta por Baptista (2014), envolvendo uma trama de trilhas a serem percorridas para a efetivação da pesquisa: saberes pessoais, saberes teóricos, usina de produção, com definição de aproximações e ações investigativas e dimensão intuitiva da pesquisa. Como aproximações, foi realizado, o resgate de saberes pessoais, com registro em diário de pesquisa, cartografia bibliográfica, rodas de conversa com o grupo de pesquisa, aproximações com o campo, com conversas informais com proprietários e hóspedes de hostels. A usina de produção envolveu também o processamento desses registros de visitas a hostels e a produção de 18 relatos de experiência da pesquisadora. Além disso, foram feitas 47 entrevistas, sistematizadas em coerência com os objetivos. Com base no referencial teórico e nos dados de campo, a pesquisa demonstra que o hostel se constitui como meio de hospedagem, em alinhamento às tendências de transformação do turismo e do setor de hospedagem. Os sinalizadores, que indicam as singularidades desse meio, remetem à busca de adequação às condições contemporâneas, bem como ao resgate de valores e ao aproveitamento de dispositivos da trama comunicacional, desde a interação direta até a utilização de recursos tecnológicos da trama midiática. Esta pesquisa vinculase ao "Amorcomtur! - Grupo de Estudos em Comunicação, Turismo, Amorosidade e Autopoiese!", e também ao projeto "Ecossistemas Turístico-ComunicacionaisSubjetivos: Sinalizadores Teórico-Metodológicos, no estudo de ecossistemas turístico-comunicacionais-subjetivos, considerados a partir de sua característica ecossistêmica, caosmótica e autopoiética", desenvolvido no Programa de PósGraduação em Turismo e Hospitalidade da Universidade de Caxias do Sul (Brasil). A pesquisa teve o apoio da Coordenação de Aperfeiçoamento de Pessoal de Nível Superior (CAPES).

10 Thomazi, M. R. (2019). Hostel: Território de Hospedagem marcado pela Trama Turístico-Comunicacional. Dissertação de Mestrado, Programa de Pós-Graduação em Turismo e Hospitalidade, Universidade Caxias do Sul, Caxias do Sul, RS, Brasil. 


\section{CONSIDERAÇÕES FINAIS}

Assim, neste ponto do texto, acredito ter motivos para honrar o título e "amar la trama mas que el desenlace". Foram apresentadas reflexões sobre as proposições Trama Ecossistêmica da Ciência, Cartografia dos Saberes e Matrizes Rizomáticas, assim como trazidos alguns exemplos de aplicação na Pesquisa em Turismo e Comunicação. Em cada trecho do percurso, procurei sinalizar para a trama, para a importância da consideração do ecossistema e, também, a partir dessas proposições epistemológico-teóricas, pretendi também sinalizar para a coerência da Cartografia dos Saberes e Matrizes Rizomáticas, para a algo que se pretende como alguma contribuição para os estudos do Turismo, mas, também, como campo transdisciplinar, para poder pensar também uma tranversalização para estudos de outras áreas.

Como foi dito, o trabalho como supervisora de texto, em diversas áreas, pela empresa, a Pazza Comunicazione, possibilitou vislumbrar também a aplicabilidade dessas proposições. Ajudou a compreender o caráter ecossistêmico e complexo, bem como a lógica processual inerente a percursos marcados pela incerteza e predominância de trajetos marcados pelo inusitado, pelo caráter efêmero, pelos fluxos, as passagens, as confluências, a condição de perder-se, muitas vezes mais que se achar... essa complexa caosmose contemporânea sinaliza para a necessidade de matrizes rizomáticas, visualidades que permitam enxergar que, mesmo no fluxo aparentemente sem rumo de acontecimentos, em meio a viagem na floresta do conhecimento, é possível encontrar vislumbres de equilíbrio fluente.

\section{REFERÊNCIAS}

Baptista, M. L. C. (2000). O Sujeito da Escrita e a Trama Comunicacional: um estudo sobre os processos de escrita do jovem adulto, como expressão da trama comunicacional e da subjetividade contemporâneas. $442 \mathrm{f}$. Tese de Doutorado em Comunicação Social, Universidade de São Paulo, São Paulo, SP, Brasil.

Baptista, M. L. C. (2014). Cartografia de Saberes na Pesquisa em Turismo: Proposições Metodológicas para uma Ciência em Mutação. Rosa dos Ventos Turismo e Hospitalidade, 6(3), 342-355.

Baptista, M. L. C. (2017). Matrizes rizomáticas: proposição de sinalizadores para a pesquisa em turismo. Anais do XIV Seminário ANPTUR - Associação Nacional de Pesquisa e PósGraduação em Turismo, Balneário Camboriú, SC, Brasil.

Barbero, J. M. (1998). De los medios a las mediaciones: comunicación, cultura y hegemonía. México: G. Gili. 
Capra, F. (1991). O Ponto de mutação. A ciência, a sociedade e a cultura emergente. São Paulo: Cultrix.

Capra, F. (1997). A Teia da vida. Uma nova compreensão dos sistemas vivos. São Paulo: Cultrix.

Colferai, S. (2014). Um Jeito Amazônida de ser Mundo. A Amazônia como Metáfora do Ecossistema Comunicacional: Uma Leitura do Conceito a Partir da Região. Tese de Doutorado, Instituto de Ciências Humanas e Sociais-ICHL, Programa de Pós-Graduação em Sociedade e Cultura na Amazônia (PPGSCA), Universidade Federal do Amazonas, Manaus, AM, Brasil.

Crema, R. (1989). Introdução à Visão Holística. Breve Relato de Viagem do Velho ao Novo Paradigma. São Paulo: Summus.

Deleuze, G., \& Guattari, F. (1995). Mil Platôs. Capitalismo e Esquizofrenia. Rio de Janeiro: Editora 34.

Drexler, J. (2017). Movimento. Recuperado de https://www.letras.mus.br/jorgedrexler/movimiento/traducao.html

Freire, P. (1996). Pedagogia da autonomia. São Paulo: Paz e Terra.

Guattari, F. (1992). Caosmose. Um Novo Paradigma Ético-Estético. Rio de Janeiro: Editora 34.

Guattari, F. \& Rolnik, S. (1986). Micropolítica: Cartografias do desejo. (2a. Ed.). Petrópolis: Vozes.

Lima, E. P. (1998). Da Escrita Total à Consciência Planetária. In: Criatividade e Novas Metodologias. São Paulo: Petrópolis.

Maturana, H. (1998). Emoções e linguagem na educação e na política. Belo Horizonte: UFMG.

Maturana, R. H., \& Varela, G. F. J. (1997). De máquinas e seres vivos: autopoiese e a organização do vivo. (3a. Ed.). Porto Alegre: Artes Médicas.

Moesch, M. M., Beni, M. C., \& Baptista. (2017). A teoria da complexidade e o ecossistema do turismo. Recuperado de www.univali.br/periodicos.

Monteiro, G. V., \& Colferai, S. A. (2011). Por uma pesquisa amazônida em Comunicação: provocações para novos olhares. In: Malcher, M., Seixas, N., Lima, R., \& Amaral Filho, O. (Eds.). Comunicação midiatizada na e da Amazônia. Belém: FADESP.

Prigogine, I. (2009). Ciência, razão e paixão. São Paulo: Livraria da Física.

Rolnik, S. (1989). Cartografia sentimental: transformações contemporâneas do desejo. São Paulo: Estação Liberdade.

Santos, B. S. (1988). Um discurso sobre as ciências. (2a. Ed.). Porto: Afrontamento.

Santos, B. S., \& Meneses, M. P. (2009). Epistemologias do Sul. Coimbra: Almedina. 
FORMATO PARA CITAÇÃO DESTE ARTIGO

BAPTISTA, M. L. C. (2020). “Amar la trama más que el desenlace!": Reflexões sobre as proposições Trama Ecossistêmica da Ciência, Cartografia dos Saberes e Matrizes Rizomáticas, na pesquisa em Turismo. Revista de Turismo Contemporâneo, 8(1), 41-64. https://doi.org/10.21680/2357-8211.2020v8n1ID18989 